\title{
The diurnal cycle of rainfall over New Guinea in convection-permitting WRF simulations
}

\author{
M. E. E. Hassim ${ }^{1, a}$, T. P. Lane ${ }^{1}$, and W. W. Grabowski ${ }^{2}$ \\ ${ }^{1}$ School of Earth Sciences and ARC Centre of Excellence for Climate System Science, \\ The University of Melbourne, Melbourne, Victoria, 3010, Australia \\ ${ }^{2}$ National Center for Atmospheric Research, Boulder, Colorado, USA \\ ${ }^{a}$ now at: Centre for Climate Research Singapore, Meteorological Service Singapore, Singapore \\ Correspondence to: M. E. E. Hassim (muhammad_eeqmal_hassim@nea.gov.sg)
}

Received: 25 March 2015 - Published in Atmos. Chem. Phys. Discuss.: 7 July 2015

Revised: 30 October 2015 - Accepted: 7 December 2015 - Published: 18 January 2016

\begin{abstract}
In this study, we examine the diurnal cycle of rainfall over New Guinea using a series of convection-permitting numerical simulations with the Weather Research and Forecasting (WRF) model. We focus our simulations on a period of suppressed regional-scale conditions (February 2010) during which local diurnal forcings are maximised. Additionally, we focus our study on the occurrence and dynamics of offshore-propagating convective systems that contribute to the observed early-morning rainfall maximum north-east of New Guinea.

In general, modelled diurnal precipitation shows good agreement with satellite-observed rainfall, albeit with some timing and intensity differences. The simulations also reproduce the occurrence and variability of overnight convection that propagate offshore as organised squall lines northeast of New Guinea. The occurrence of these offshore systems is largely controlled by background conditions. Days with offshore-propagating convection have more middle tropospheric moisture, larger convective available potential energy, and greater low-level moisture convergence. Convection has similar characteristics over the terrain on days with and without offshore propagation.

The offshore-propagating convection manifests via a multi-stage evolutionary process. First, scattered convection over land, which is remnant of the daytime maximum, moves towards the coast and becomes reorganised near the region of coastal convergence associated with the land breeze. The convection then moves offshore in the form of a squall line at $\sim 5 \mathrm{~ms}^{-1}$. In addition, cool anomalies associated with gravity waves generated by precipitating
\end{abstract}

land convection propagate offshore at a dry hydrostatic gravity wave speed (of $\sim 15 \mathrm{~ms}^{-1}$ ) and act to destabilise the coastal/offshore environment prior to the arrival of the squall line. Although the gravity wave does not appear to initiate the convection or control its propagation, it should contribute to its longevity and maintenance. The results highlight the importance of terrain and coastal effects along with gravity waves in contributing to the diurnal cycle over the Maritime Continent, especially the offshore precipitation maxima adjacent to quasi-linear coastlines.

\section{Introduction}

The diurnal cycle of rainfall is the most fundamental mode of tropical internal variability. Across the Maritime Continent (MC), convective activity is widespread, exhibiting distinct spatial patterns and strong daily contrasts between land and the surrounding seas. Precipitation over land peaks in the afternoon to early evening. Conversely, while there is relatively little amplitude in the diurnal cycle of rainfall over the open ocean, secondary rainfall maxima are seen near the coasts of many MC islands (e.g, Kikuchi and Wang, 2008).

These offshore rainfall concentrations are most prominent near the land-sea boundaries of Sumatra, Borneo, Java, and New Guinea during pre-dawn hours, where sharp gradients in coastal precipitation frequencies are seen in very highresolution data derived from the Tropical Rainfall Measuring Mission (TRMM) precipitation radar (PR) data set (Biasutti et al., 2012). Using high-resolution brightness temper- 
ature data, Yang and Slingo (2001) noted that diurnal convective variations over the major islands (viz. New Guinea and Sumatra) spread out coherently into adjacent coastal seas over a few hundred kilometres. They speculated that seaward propagating disturbances (viz. gravity waves of varying depths) could be responsible for the signal spreading. However, the details of processes leading to offshore rainfall were not explored. More recent studies have since confirmed not only the night time offshore propagation signal but also an afternoon inland migration from the coastline due to systems initiated along the sea breeze front (Mori et al., 2004; Zhou and Wang, 2006; Kikuchi and Wang, 2008). Both onshore and offshore rainfall features do vary with large-scale conditions, such as through variations in phase of the MaddenJulian Oscillation (e.g. see Peatman et al., 2014). However, they are persistent features nonetheless.

Notably, all the major islands in the Maritime Continent have significant topography located near the coast. The presence of steep terrain generates localised circulations in response to solar heating - in particular, upslope winds - that, in turn, initiate convection over the mountains in the early afternoon (Qian, 2008). As the sea breeze develops and penetrates inland during the afternoon, superposition of the sea breeze front with upslope flows helps to feed the existing convection, promoting further development over the mountain slopes (e.g. Zhou and Wang, 2006; Wu et al., 2008; Barthlott and Kirshbaum, 2013).

However, the processes that lead to nocturnal precipitating systems over adjacent coastal seas appear to be less straightforward. For example, converging land breezes from neighbouring landmasses are proposed for cases of early-morning convection seen in Van Diemen Gulf north-east of Darwin (Wapler and Lane, 2012) and over the Java sea (Qian, 2008). Meanwhile, Fujita et al. (2010) concluded that the night time rainfall maximum seen in the Strait of Malacca is due to the interaction between the land breeze and downslope winds from the mountainous areas of Sumatra and the Malay Peninsula. In addition, the regular appearance of nocturnal coastal convection north-west of Borneo is attributed to surface convergence between the land breeze and the winter monsoonal flow (Houze et al., 1981) and, more recently, to intense offshore surface flows due to convectively induced boundary layer thermal gradients (Wu et al., 2008). The latter mechanism is also invoked to explain the abundance of rainfall offshore near western Sumatra (Wu et al., 2009). Finally, Love et al. (2011) demonstrate the importance of offshorepropagating gravity waves in contributing to the formation of precipitation offshore. They invoke a combination of the diurnally forced gravity waves described by Mapes et al. (2003) and convectively generated (stratiform) cooling as the source of these waves. Given the variations in spacing and the complex orientation and topography of the MC islands, it is plausible that different mechanisms may operate to produce nocturnal offshore rainfall at different coastal locations in the Maritime Continent region.
New Guinea is the largest island within the Maritime Continent. It also has the steepest and highest orography of all the major MC islands, with peaks exceeding $3000 \mathrm{~m}$ (Fig. 1a). The primary mountain chain forms the island's "spine" and runs parallel to the northern coastline, which is quasi-linear and aligned in a north-west-south-east direction much like the coast of western Sumatra. A much lower ridge is situated next to the northern coast, with peaks largely between 250 and $750 \mathrm{~m}$. The topography of New Guinea is therefore analogous to that of Sumatra in the western MC, except that Sumatra has higher mountains $(\geq 1000 \mathrm{~m})$ next to its western coast.

In this paper, we examine the diurnal cycle of rainfall over New Guinea using convection-permitting simulations with the Weather Research and Forecasting (WRF) model. One aim of the paper is to examine the dynamics and occurrence of propagating convective signals that lead to the early-morning offshore precipitation maxima. Our focus is on a 1-month period (February 2010) during the "year of tropical convection" (YOTC; Moncrieff et al., 2012), which has suppressed large-scale convective conditions; this period is chosen in an attempt to isolate the localised island forcing.

The remainder of the paper is organised as follows. The next section (Sect. 2) describes the model set-up and numerical experiments. Section 3 reports on the convectionpermitting simulations. Analysis between occurrences of offshore rainfall propagation and times when it is lacking is discussed in Sect. 3.2, including the dynamical mechanisms associated with the convective systems over the sea. Finally, Sect. 4 provides a summary and concluding remarks.

\section{WRF simulations}

\subsection{Model set-up}

Simulations are conducted using version 3.3 of the WRF Advanced Research Core (WRF-ARW) (Skamarock et al., 2008) with a one-way nested configuration (Fig. 1). Most of this study focuses on a two-domain set-up with an outer domain $(\mathrm{d} 01)$ that has $540 \times 420$ grid points with a $12 \mathrm{~km}$ grid spacing and a second domain (d02) consisting of $840 \times$ 990 grid points and a $4 \mathrm{~km}$ grid spacing. The second domain is centred on the southern parts of New Guinea and covers a large portion of northern Australia; the domain includes Darwin, which is used for additional evaluation considered later. Additional simulations are also conducted with a third domain $(\mathrm{d} 03)$ with $1.33 \mathrm{~km}$ grid spacing $(1830 \times 2190$ grid points, dashed box in Fig. 1a) that is nested within $\mathrm{d} 02$.

All model domains have 80 vertical levels with a model top of $10 \mathrm{hPa}$ ( $\sim 30 \mathrm{~km}$ in altitude). A $10 \mathrm{~km}$ deep Rayleighfriction sponge layer is used to minimise the reflection of upward-propagating gravity waves generated by convection. A stretched vertical grid is used, with grid spacing between 50 and $300 \mathrm{~m}$ in the lowest $4 \mathrm{~km}$, then averaging $\sim 300 \mathrm{~m}$ 

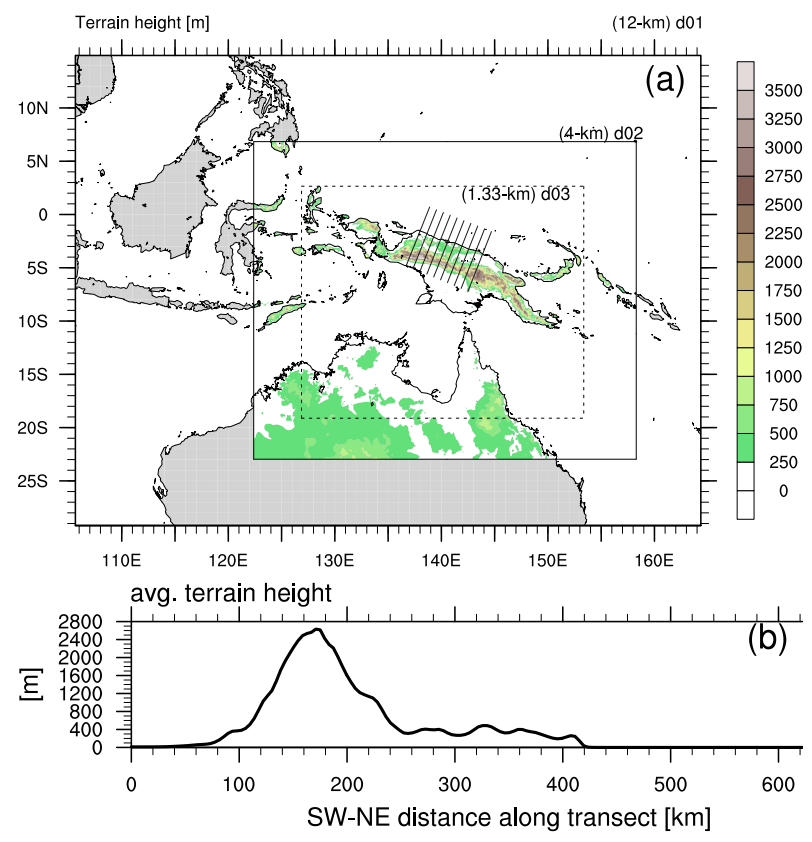

Figure 1. (a) Model domains and orography. The profile shown in panel (b) represents the mean terrain height (m), as averaged across the line sections shown in panel (a).

between 4 and $14 \mathrm{~km}$ before varying exponentially to $600 \mathrm{~m}$ by $20 \mathrm{~km}$. This set-up ensures reasonably high resolution in the vertical, although many unresolved turbulent processes remain. The vertical velocity damping option is also used to prevent the model from becoming unstable with large vertical velocities over steep terrain. Initial conditions are provided by the European Centre for Medium-Range Weather Forecasts interim (ERA-Interim) reanalysis data (Dee et al., 2011) at $0.75^{\circ} \times 0.75^{\circ}$ resolution. Lateral boundary conditions for the outer $12 \mathrm{~km}$ domain and sea-surface temperatures for all domains are prescribed every $6 \mathrm{~h}$ from ERAInterim data. The model time steps are $30 \mathrm{~s}$ for $\mathrm{d} 01,10 \mathrm{~s}$ for $\mathrm{d} 02$, and $3.3 \mathrm{~s}$ for $\mathrm{d} 03$.

The simulations utilise various physical parameterisations. These include the Noah land surface model, the Goddard scheme for shortwave radiation, the Rapid Radiative Transfer Model for longwave radiation, and the Mellor-YamadaJanjic (MYJ) 2.5 level planetary boundary layer (PBL) scheme. The MYJ PBL scheme is used in conjunction with the Janjic Eta Monin-Obukhov surface layer scheme. Radiation calls are made every $10 \mathrm{~min}$ on both domains. Subgrid-scale convection in the $12 \mathrm{~km}$ outer domain is parameterised by the Kain-Fritsch cumulus scheme. The inner domains ( $\mathrm{d} 02$ and $\mathrm{d} 03$ ) are considered convection permitting and moist processes are treated explicitly. Cloud microphysical processes are represented with the WRF Single-Moment 6-Class (WSM6) scheme.

\subsection{Description of experiments and data}

Unless otherwise noted, the results reported herein are from five overlapping simulations that are conducted in sequence to cover the period between 12:00 UTC, 1 February 2010, and 12:00 UTC, 28 February 2010. These overlapping simulations use d01 and d02 only. Each simulation is performed separately and then concatenated to constitute the month. This period was chosen because the eastern $\mathrm{MC}$ region experienced suppressed regional-scale conditions coinciding with an active Madden-Julian Oscillation (MJO) phase in the Pacific Ocean in early February transitioning to an inactive MJO in late February (M. Wheeler, personal communication, 2013); thus local diurnal forcings are maximised and sub-monthly variability can be seen.

The five simulations span the following time slices: (1) 12:00 UTC, 1 February-23:00 UTC, 6 February (T1); (2) 12:00 UTC, 6 February-23:00 UTC, 11 February (T2); (3) 12:00 UTC, 11 February-23:00 UTC, 16 February (T3); (4) 12:00 UTC, 16 February-23:00 UTC, 21 February (T4); and (5) 12:00 UTC, 21 February-12:00 UTC, 28 February (T5).

Model output is saved hourly but the first $12 \mathrm{~h}$ of each simulation are regarded as spin-up and not used. Results are analysed for the period 00:00 UTC, 2 February-23:00 UTC, 27 February, and only for the inner $4 \mathrm{~km}$ domain. A smooth contiguous span of model data for the analysis is ensured by appending consecutive time slices such that the 23:00 UTC, 6 February, data of T1 is followed by 00:00 UTC, 7 February, data of T2, and 23:00 UTC, 11 February, data of T2 is followed by 00:00 UTC, 12 February, data of T3, etc. Note the overlap addresses the precipitation spin-up problem that models generally suffer from and allows model flow fields to properly adjust to imposed boundary conditions.

The rationale of running separate time slices with reinitialised conditions as opposed to a single, continuous run (i.e, "free-running") for the chosen period is because previous studies show that the representation of observed events is sensitive to the initialisation time as simulations with longer lead times perform poorly (e.g. Wapler et al., 2010, and Wapler and Lane, 2012). A continuous run is known to produce the lowest skill (e.g. Lo et al., 2008).

In addition to the above-described overlapping simulations, another simulation is completed with the three (oneway nested) domains for the purposes of assessing the resolution sensitivities. Because of the much higher computational cost, this set-up was only run for 14 consecutive days (12:00 UTC, 1 February-12:00 UTC, 15 February), with the first $12 \mathrm{~h}$ excluded from the analysis due to spin-up issues. This is hereafter referred to as the "free-running" simulation.

A compositing technique is used to evaluate the simulated diurnal cycle, following the example of May et al. (2012). Specifically, the mean diurnal cycle is constructed by averaging all values at a particular time of day and the mean day 

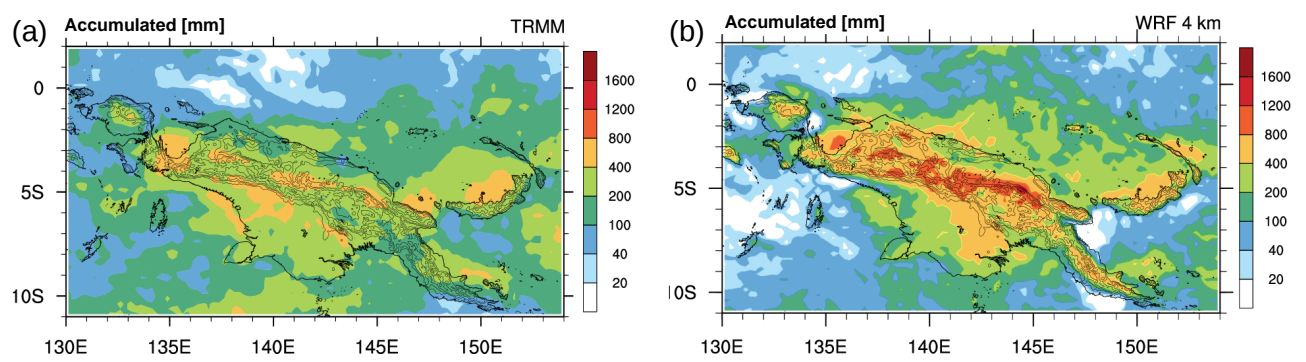

Figure 2. Accumulated rainfall (mm) for the New Guinea region between 2 and 28 February 2010 from TRMM (a) and the 4 km WRF simulation (b). Data from WRF have been coarse-grained to match the data resolution of the TRMM 3B42 gridded product.

is constructed by a series of such averages. Such an approach is also used to analyse the observational data.

Modelled precipitation patterns for New Guinea are assessed with the TRMM 3B42 version 7 gridded rainfall data set (Huffman et al., 2010). 3B42 data are a blended rainfall product, derived from a complex combination of TRMM PR estimates and satellite data obtained from other passive sensors (microwave and infrared). Final estimates are scaled to match monthly rain gauge values. The merged data product consists of 3-hourly centred averages and has a spatial resolution of $0.25^{\circ} \times 0.25^{\circ}$, which makes it suitable to study diurnal spatial patterns of tropical rainfall. Modelled rainfall is coarse-grained to the same temporal and spatial resolution whenever it is compared to TRMM.

Rainfall observations inferred from the Darwin (Gunn Point) C-band polarimetric radar (CPOL) are also used to evaluate the model. The rainfall rates are derived from radar reflectivities using the algorithm described by Bringi et al. (2001) and calibrated against gauge measurements. The data are at $2.5 \mathrm{~km}$ horizontal resolution within a $150 \mathrm{~km}$ radius of the radar location.

\section{Results}

\subsection{Observed and simulated diurnal features}

\subsubsection{Spatial distribution}

The observed total rainfall over New Guinea for the period 2-28 February is presented in Fig. 2a. Most of the precipitation falls over high terrain with maxima concentrated along the slopes. Large amounts of rainfall also occur along concave coastal bights. The occurrence of these offshore maxima are attributed to the enhanced convergence effect due to the inward curvature of coastlines (Biasutti et al., 2012). Substantial rainfall accumulations are also seen near the northern coast between 139 and $144^{\circ}$, extending about $200 \mathrm{~km}$ offshore in the Bismarck Sea. Daily mean rates range from 8 to $12 \mathrm{~mm} \mathrm{day}^{-1}$ in that region. These high rainfall rates are concentrated along a relatively linear stretch of coastline where there is no enhanced localised convergence from colliding land breezes. Interestingly, the location of these rainfall rates coincides well with the offshore maximum in diurnal brightness temperature difference reported by Liberti et al. (2001) (their Fig. 4), who documented the life cycle of convective cloudiness for New Guinea using infrared satellite data. The physical mechanism responsible for that coastal rainfall maximum is discussed in Sect. 3.2.2.

The corresponding accumulated rainfall amounts simulated by WRF at $4 \mathrm{~km}$ is shown in Fig. 2b. These have been coarse-grained both spatially and temporally to match the TRMM 3B42 data (i.e. a 3-hourly centred average) to facilitate proper comparison. WRF captures the observed spatial distribution of rainfall, albeit with higher modelled intensity over much of the region. This is most evident over the mountain slopes, where total rainfall amounts and mean daily rates are more than double those observed by TRMM at some locations. Less bias is seen for the coastal regions, especially for our area of interest along the northern coast.

The excessive rainfall over the slopes is partly due to the horizontal grid spacing, which at $4 \mathrm{~km}$ is still too coarse to resolve individual convective updrafts and gives a smoothed topography. This results in wide clouds in the simulations that do not entrain as much. Nonetheless, measurements by TRMM over steep topography should also be treated with caution, when considering the model rainfall biases over elevated terrain. Recently, Matthews et al. (2013) reported that TRMM underpredicted rainfall over high-terrain by as much as $50 \%$ when compared to long-term rain-gauge station data in the New Guinea highlands. Additional results by Chen et al. (2013) show similar underestimates of intense rainfall over high terrain (Hawaii). These studies therefore suggest that disparity between actual and simulated amounts (at least over elevated land) may be less than is apparent from Fig. 2.

To evaluate the simulated rainfall further, comparisons are made between diurnal composites derived from the WRF free-running simulation, the CPOL radar-derived rainfall, and TRMM over the $150 \mathrm{~km}$ radius area surrounding the Darwin CPOL radar (Fig. 3). Note these composites are over a limited number of days due to missing data. The figure shows that at $4 \mathrm{~km}$ resolution $(\mathrm{d} 02)$ the daily maximum rainfall rate from WRF is in good agreement with 

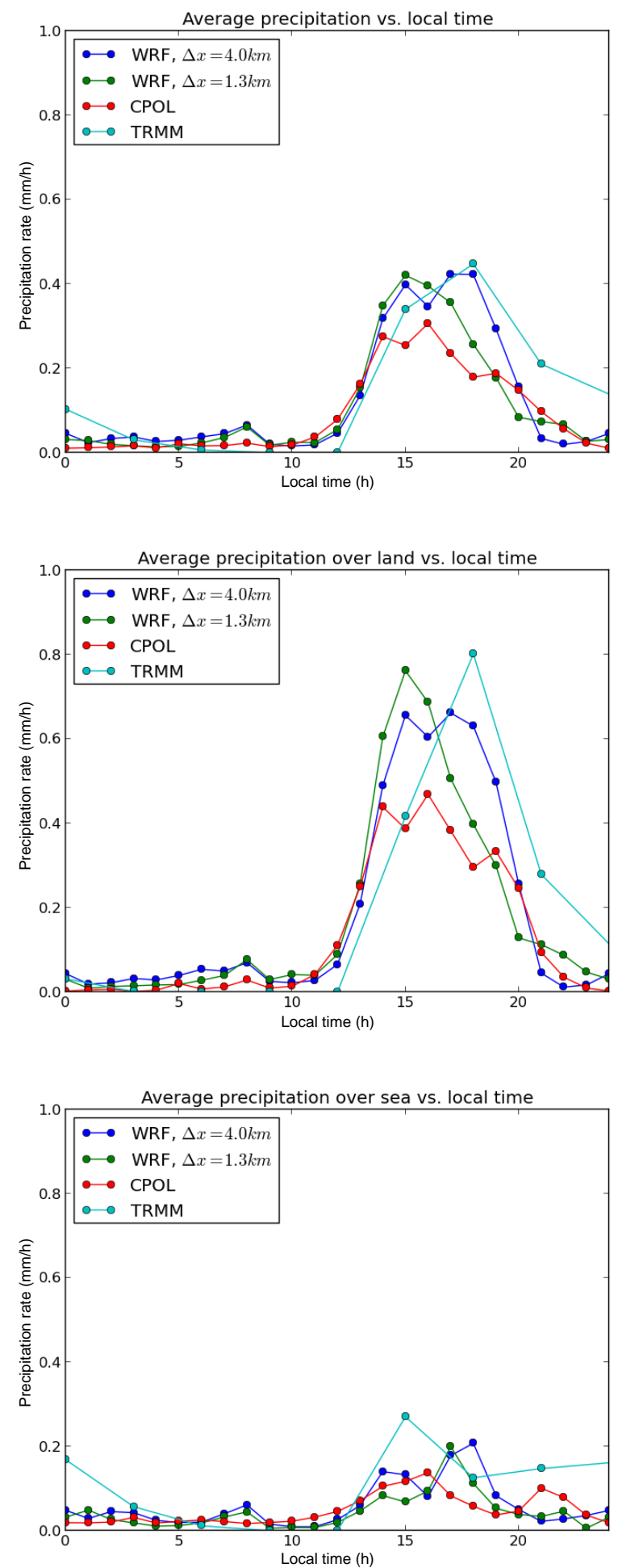

Figure 3. Comparison of simulated diurnal rainfall at 4 and $1.33 \mathrm{~km}$ resolutions with TRMM and radar-derived precipitation (CPOL) around Darwin, Australia, area averaged over the entire horizontal coverage (top), over land (middle), and over sea points (bottom) within the radar domain respectively. The mean diurnal cycle is composited using days 2-9 and 11-12 February.
TRMM over Darwin, except the model leads TRMM by a few hours. The model shows better agreement with regards to the timing of rainfall when compared to CPOL but has larger rainfall amounts than CPOL. The CPOL underestimation is likely due to temporal sampling issues that miss the most intense rainfall events, and TRMM 3B42 is known to have issues regarding a delayed timing of rainfall compared to other rainfall products (S. Rauniyar, personal communication, 2014). This comparison provides additional confidence in the simulation results and suggests that the issues over New Guinea are related to the terrain. The differences may derive from model overproduction of rain on the mountain slopes, TRMM underestimates of rainfall over terrain, or a combination of the two. In addition, WRF has a slight tendency to overproduce the early-morning convection near Darwin (similar to what Wapler et al., 2010 found). This may explain why offshore precipitation to the north-east of New Guinea is slightly larger than observed as shown in Fig. 2.

\subsubsection{Diurnal features}

The behaviour of diurnal rainfall over New Guinea is shown by Fig. 4. This figure shows time-distance (Hovmöller) plots of 3-hourly surface rainfall, averaged across the line sections seen in Fig. 1a. Month-long diagrams from TRMM and WRF are depicted in coordinated universal time (UTC) (Fig. 4a and $b$ ), while the average diurnal cycle for each are shown in local time (Fig. 4c and d). The heaviest observed daily rainfall is over land and occurs along the mountain slopes rather than directly over the peaks (in both simulations and observations). On some days (e.g. 3 and 23-26 February), offshore propagation of rainfall from the northern coast is very prominent. The precipitation signal over water is largest $(\geq$ $2.5 \mathrm{~mm}$ ) when it appears to originate from land (Fig. 4a). The regular signal suggests that most of the accumulated rainfall offshore near the northern coast during February 2010 comes mainly from organised propagating convective systems that developed over land rather than from cells which initiate over water. Nonetheless, there are also consecutive days when little or no offshore propagation is seen, despite there being inland convection in the afternoon (e.g. 11-15 February). The behaviour of these offshore-propagating convective systems and the roles of gravity waves initiating or modulating them are presumably sensitive to the large-scale state (e.g. the MJO phase). This will be considered in a future publication.

The mean diurnal cycle from TRMM (Fig. 4c) shows daily rainfall being initiated in the early afternoon over the mountain ridge before intensifying and migrating downslope towards the coast by early evening local time (LT). One signal moves south-westwards while the other signal moves towards the northern coast. The northern signal maximises at midnight over the gentler slopes around $140 \mathrm{~km}$ inland from the coast. The signal then continues to propagate offshore from early- to mid-morning LT the next day, maximising be- 

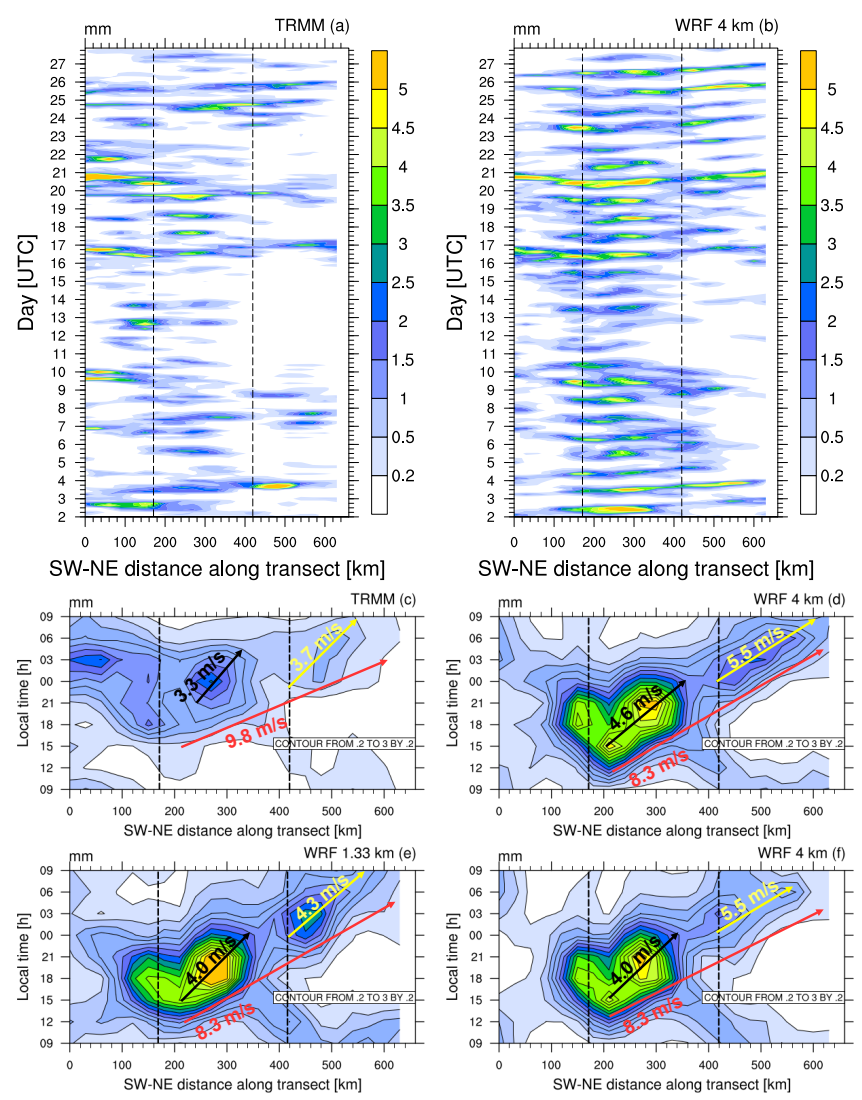

Figure 4. Time-distance plots of 3-hourly mean rainfall, averaged across the line sections in Fig. 1a, from (a) TRMM and (b) $4 \mathrm{~km}$ WRF for the period 2-28 February 2010. The mean diurnal cycle in local time, composited using 3-hourly data, is also shown for (c) TRMM, (d) $4 \mathrm{~km}$ (re-initialised runs), (e) $1.33 \mathrm{~km}$, and (f) $4 \mathrm{~km}$ 2-week free-running WRF runs. Vertical dashed lines represent the positions of the averaged mountain peak (about $170 \mathrm{~km}$ ) and northern coastline (about $420 \mathrm{~km}$ ) respectively. Coloured lines show the estimated phase speeds for the peak rain signals over land (black), over water (yellow), and for the broader rain envelope (red).

tween 60 and $80 \mathrm{~km}$ from the coast (Fig. $4 \mathrm{c}$ ). There is also a rainfall disturbance propagating from the coast to the mountains in the late morning and early afternoon. This refers to onshore convection that develops and slowly migrates inland following the penetration of the sea breeze. This diurnal feature is characteristic of coastal environments around the islands of the Maritime Continent and has been documented for New Guinea in previous studies (e.g. Zhou and Wang, 2006).

Overall, there are some notable similarities between the model and observations as WRF captures the gross spacetime structure of the observed diurnal patterns reasonably well. This includes the sub-monthly variability of offshore rainfall (Fig. 4b), the inland migration of late-morning/earlyafternoon rainfall from the coast, and the location of peak rainfall over land; i.e. the rainfall maximum is first seen near the mountain tops before moving down the slopes (cf. Fig. 4c and d). The timing and location of the simulated earlymorning rainfall maximum offshore compare favourably to TRMM. However, precipitation development and timing of peak rainfall over land occurs by about $3 \mathrm{~h}$ too early in the model and modelled signals are considerably more intense over the slopes, with offshore rainfall also being too heavy. Some of these differences can be explained in the context of the comparisons over Darwin presented earlier. Moreover, with the exception of the timing of the absolute rainfall maximum, most of the apparent differences between the model and TRMM in Fig. 4 are related to a difference in the rainfall intensity.

In our assessment, estimated phase speeds of the peak rain signal and for the broader envelope do not differ much between TRMM and WRF in the diurnal mean (Fig. 4c-f). Furthermore, drawing a line between the peak over land and the peak over the ocean does not properly represent the propagation speed of the systems - convection over land and over water are part of different morphologies. Due to likely timing/intensity bias over terrain, the peak rainfall signal from TRMM $\left(3.3 \mathrm{~m} \mathrm{~s}^{-1}\right)$ moves slightly slower over land than in WRF $\left(4.6 \mathrm{~m} \mathrm{~s}^{-1}\right)$. The faster peak signal seen offshore from WRF ( $5.5 \mathrm{~m} \mathrm{~s}^{-1}$ compared to TRMM at $3.7 \mathrm{~m} \mathrm{~s}^{-1}$ ) is possibly due to there being more simulated squalls in the later part of the month. Arguably, compositing the much coarserresolution TRMM product could also imply a slightly faster propagation speed for the broader convective envelope. We acknowledge that propagation speed differences between TRMM and WRF could be the result of simulation bias, perhaps related to errors in the convection characteristics. However, it is more likely a combination of timing/intensity bias from the observations, simulation bias, and the effect of coarse-graining the model output. However, despite these biases, the timing and occurrence of the offshore-propagating rainfall is well-represented and therefore this model experiment is well-suited to study the dynamics of the processes at play governing the offshore precipitation.

\subsubsection{Sensitivity to model resolution}

Admittedly, the $4 \mathrm{~km}$ horizontal grid spacing of d02 is relatively coarse and some of the differences between the simulation and the observations could be explained by these numerical issues. For example, $4 \mathrm{~km}$ resolution does not properly resolve the boundary layer thermals and shallow moist convection and necessitates parameterisation of these processes. Moreover, although deep convection is treated explicitly in these simulations the convective processes are not properly resolved (they are "permitted"). This should lead to convective updrafts that are too wide and intense, in part because of the lack of explicit entrainment and the smoothed topography, which might explain the rainfall intensity bias. To consider these issues regarding model resolution, we compare the results from the $4 \mathrm{~km}(\mathrm{~d} 02)$ and $1.33 \mathrm{~km}(\mathrm{~d} 03)$ simulation domains from the free-running simulation. These domains 

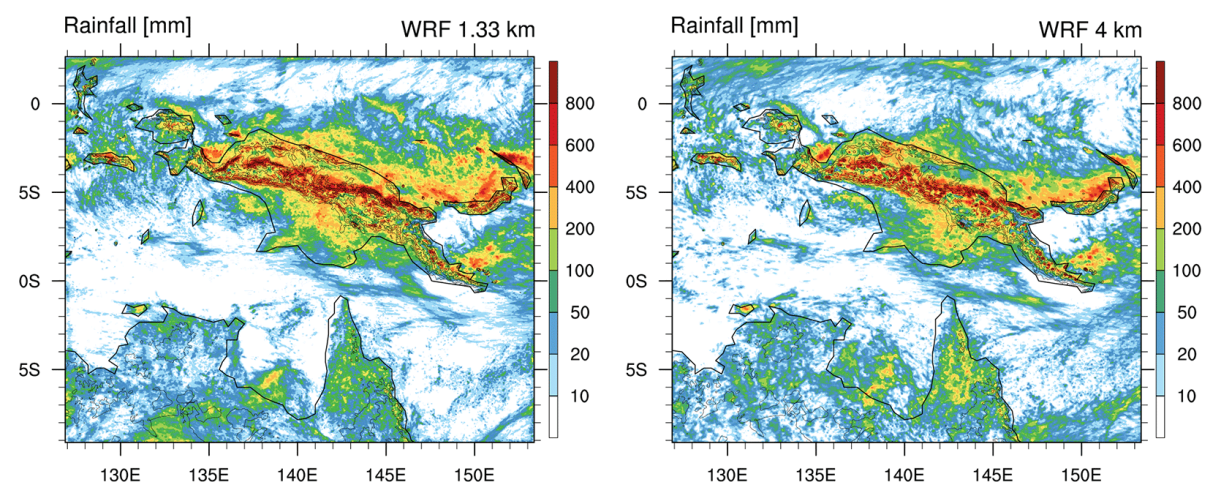

Figure 5. Two-week rainfall accumulations from the (a) $1.33 \mathrm{~km}$ and (b) $4 \mathrm{~km}$ free-running model simulations in domain 3 (d03) at their native grid resolutions.

can be compared directly because of the one-way nesting configuration, which uses $\mathrm{d} 02$ to force only the lateral boundary conditions of d03. Of course, even at $1.33 \mathrm{~km}$ grid spacing many of the important processes like shallow convection remain poorly resolved.

Comparison of the 2-week rainfall accumulations over the area of d03, on each model's native grid, demonstrates notable similarity between the two resolutions (Fig. 5). Both model resolutions show similar rainfall accumulations over the slopes of New Guinea, both in terms of intensity and area. Perhaps the largest difference is that the higher-resolution d03 produces slightly more rainfall immediately offshore of the northern coast.

Comparisons of the mean diurnal cycle and its spatial distribution over New Guinea from d02 and d03 (Fig. 4e and f) shows that there is limited sensitivity to the resolutions considered here. The rainfall intensity is slightly larger, for both the diurnal peak and offshore maximum, in the higher-resolution model. Thus, reducing the grid spacing to $1.33 \mathrm{~km}$ does not improve the biases compared to TRMM. In terms of the individual convective systems, inspection of the modelled clouds and rainfall that propagate offshore (not shown) demonstrate increased organization at higher resolution. Over Darwin (Fig. 3) there is a similar change in precipitation intensity over land, with the increased resolution leading to a slightly larger rainfall maximum. However, because of the relatively short record used in the comparisons here, many of these differences may not be representative of the actual sensitivities. For this reason, and the apparent lack of systematic improvement with higher resolution, we focus the remaining analysis on the longer simulation data set provided by the $4 \mathrm{~km}$ WRF (overlapping) simulation.

\subsection{Emergence of the offshore rainfall maximum}

\subsubsection{Offshore vs. no-offshore days}

The contrast between modelled days of significant offshore rainfall and days when it is lacking warrants further attention.
Here, we examine the various conditions that may explain the offshore rainfall maximum near the northern coast as seen in Fig. 2a and b. With guidance from Fig. $4 a$ and $b$ and inspection of hourly simulated rainfall maps (not shown), we have selected days 3 and 23-26 February to form the composite of offshore rainfall propagation days (designated simply as offshore). Likewise, days 11-15 February are chosen to form the composite of days when offshore propagation is absent (denoted no-offshore). The selected offshore and no-offshore days in the model simulation are chosen for their general agreement with TRMM data as seen in the Hovmöller diagram in Fig. 4. The mean diurnal cycle of rainfall in LT for each these composites is depicted in Fig. 6, constructed using the compositing technique described in Sect. 2.2.

The offshore diurnal cycle is similar to the mean diurnal cycle for February (Fig. 6a), indicating that large-scale conditions favourable for the occurrence and propagation of offshore rainfall are the norm in day-to-day variability for the period studied. The most intense rainfall signal near the coast has a coherent propagation that begins about $50 \mathrm{~km}$ inland and extends about $120 \mathrm{~km}$ offshore. The speed of the strongest signal (marked on Fig. 6a) is about $4.7 \mathrm{~m} \mathrm{~s}^{-1}$, while the speed corresponding to the rainfall onset is around $8 \mathrm{~m} \mathrm{~s}^{-1}$ (see Fig. 12b also). This value corresponds to the propagation speed of the "gust-font" mode identified by Tulich and Mapes (2008) in their two-dimensional cloudresolving study. We discuss the significance of this mode in Sect. 3.2.3.

The rainfall patterns closer to the terrain peak move slower, but they have less coherent propagation characteristics. During no-offshore days (Fig. 6b) the rainfall near the terrain peak shows similar characteristics to offshore days, albeit with slightly slower propagation speeds, but terminates within about $100 \mathrm{~km}$ of the coast. While some rain can be seen more than $120 \mathrm{~km}$ offshore between 03:00 and 09:00 LT, the signal does not appear to follow coherent propagation from land as it does in the offshore days. This may be a signal of the open ocean diurnal cycle and not related to offshore propagation per se. 

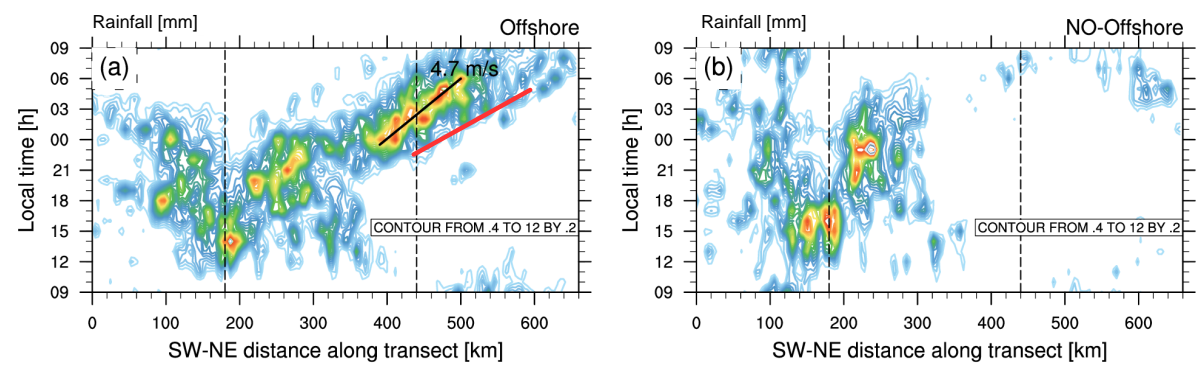

Figure 6. Composite diurnal cycle in local time (LT) in simulated (a) offshore and (b) no-offshore days, as averaged across the line sections seen in Fig. 1a. The black line represents the estimated phase speed of the peak rain signal across the northern coast, while the red line denotes the estimated phase speed of the broader rain envelope $\left(\sim 8 \mathrm{~ms}^{-1}\right)$. Vertical dashed lines mark the terrain peak and the coast as in Fig. 4.
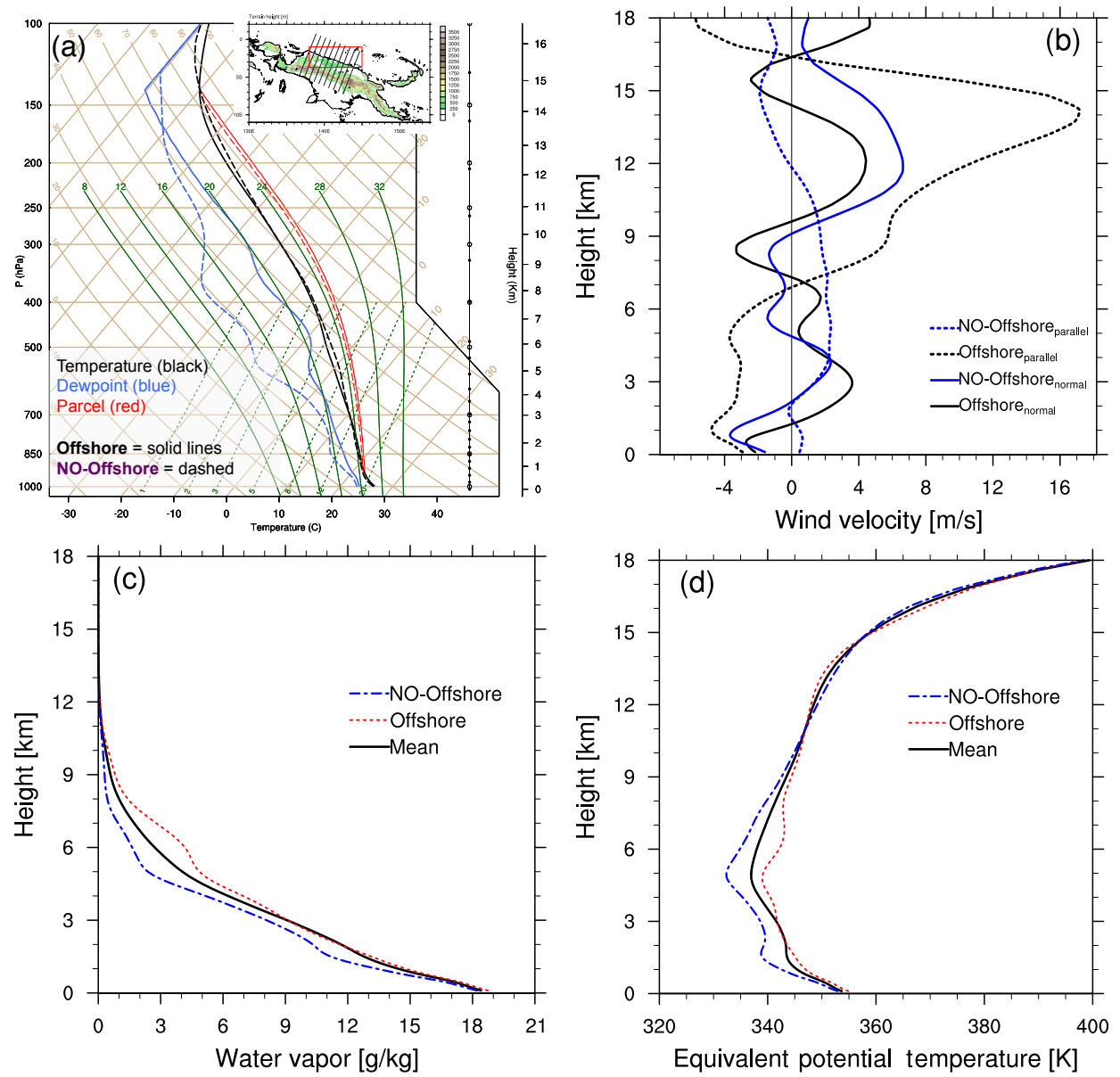

Figure 7. Mean profiles averaged within the region denoted by the red box in the inset. (a) Simulated temperature (black), dew point (blue) and parcel temperature (red) averaged for offshore (solid) and no-offshore (dashed) days. (b) Vector wind in the direction normal (solid) and parallel (dashed) to the coast on offshore (black) and no-offshore (blue) days. Positive values of normal velocity flow towards the north-northeast and parallel velocity flow towards the west-north-west. (c) Water vapour mixing ratio $\left(\mathrm{g} \mathrm{kg}^{-1}\right)$ and (d) equivalent potential temperature (K) for offshore and no-offshore days compared to the February mean.

Inspection of the environmental conditions averaged for a box region around the northern coast provides us with an explanation for the difference in convective behaviour during offshore days compared to no-offshore. Figure 7a shows the mean profiles of simulated temperature and dew point, along with parcel temperatures for offshore and no-offshore days for the area within the denoted red box. The wind components normal and parallel to the terrain, water vapour, and 
equivalent potential temperature are also shown (Fig. 7b-d). The plot shows that both offshore and no-offshore days possess minor differences in their temperature profiles, but nooffshore days are much drier especially above $700 \mathrm{hPa}(\sim$ $3 \mathrm{~km}$ ) as shown by the large dew point depression (Fig. 7a), and large differences in water vapour and equivalent potential temperature at around $6 \mathrm{~km}$ (Fig. 7c and d). In fact, the middle troposphere on no-offshore days has a lower water vapour content than the monthly mean, compared to offshore days when it is anomalously moister (Fig. 7c). The coastal/offshore environment on no-offshore days is therefore less likely to support deep convection at night despite having moderate convective available potential energy (CAPE, $\sim 1400 \mathrm{~J} \mathrm{~kg}^{-1}$ ). This is evident in the much shallower cloud layer for the region near the northern coast on no-offshore days (see Fig. 11 later). In contrast, considerably larger CAPE exists on offshore days $\left(\sim 2100 \mathrm{~J} \mathrm{~kg}^{-1}\right)$.

The mean wind profiles normal to the coast show little variation in low-level wind speed below $500 \mathrm{~m}$, which is directed onshore, or shear below $3 \mathrm{~km}$, which is directed offshore. Shear values between 1 and $3 \mathrm{~km}$ are 0.0025 and $0.00235 \mathrm{~s}^{-1}$ on no-offshore and offshore days respectively. There is stronger shear above $6 \mathrm{~km}$ in offshore cases. Notably, there are speed and directional differences at low levels for wind parallel to the northern coast. These could have an important effect on the moisture flux convergence in the boundary layer along the coast.

To examine the evolution of low-level moisture supply over the northern coast on both offshore and no-offshore days, we calculate the total horizontal moisture flux convergence (or simply moisture convergence) by summing all grid points between the surface and a height of about $1 \mathrm{~km}$ (first 11 models levels) in the region denoted by the red box (see inset in Fig. 7a). We define this vertically integrated moisture convergence (VIMFC) using

VIMFC $=-\int_{z=\mathrm{sfc}}^{z=1 \mathrm{~km}}[\nabla \cdot(q \boldsymbol{V})]$,

where $q=$ specific humidity $\left(\mathrm{g} \mathrm{kg}^{-1}\right)$ and $\boldsymbol{V}=$ vector wind $\left(\mathrm{m} \mathrm{s}^{-1}\right)$. The divergence at each grid point is approximated using centred finite differences. Both offshore and nooffshore days feature a significant diurnal cycle in moisture convergence, with maximum in the evening/early morning (Fig. 8). The VIMFC on offshore days is substantially larger than on no-offshore days and precedes the rainfall maximum by a few hours. Most of this VIMFC difference can be attributed to the difference in boundary layer mass convergence since mean moisture content in the first $1 \mathrm{~km}$ is similar on nooffshore and offshore days (Fig. 7a). Of course, some of the VIMFC differences, especially in the hours that correspond to the coastal rainfall, may be convectively induced. However, it is important to note that during the mid-afternoon (around 15:00 LT) when both the offshore and no-offshore

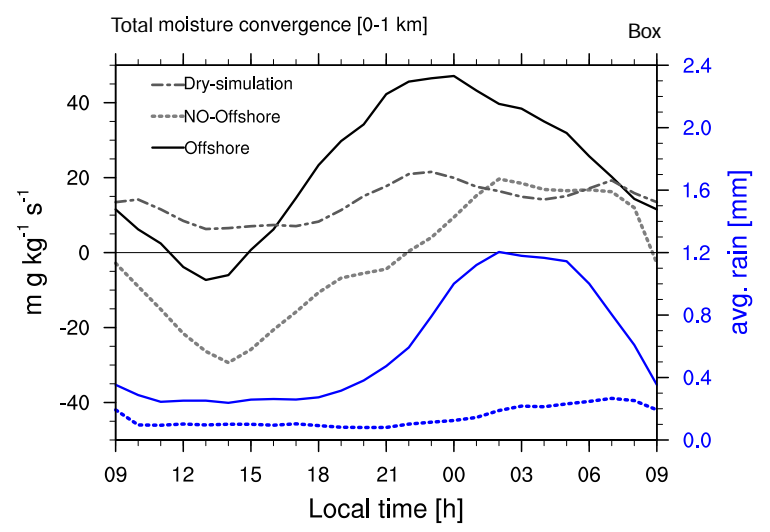

Figure 8. Total moisture convergence (VIMFC, $\mathrm{m} \mathrm{kg}^{-1} \mathrm{~s}^{-1}$ ), vertically integrated between surface and $1 \mathrm{~km}$ height (first 11 model levels), for the red box region shown in Fig. 7a (black lines). Area of the box is $290048 \mathrm{~km}^{2}(88 \times 206$ grid points $)$. The diurnal areaaveraged rainfall for offshore and no-offshore days are shown by the solid and dotted blue lines respectively.

days have active convection, the offshore days have almost zero convergence whereas the no-offshore case is divergent. This suggests that regional-scale conditions, whether they be boundary layer convergence or mid-level moisture (as discussed above), are playing an important role in delineating offshore from no-offshore days. Arguably, the substantially larger CAPE on offshore days is due to the increased boundary layer moisture convergence between 15:00 LT and midnight (Fig. 8).

In order to isolate the convectively generated perturbations (gravity wave) response from that solely due to the diurnal heating and cooling of the elevated land, we performed an additional sensitivity experiment in which temperature tendencies from cloud microphysical processes were disabled (i.e. a dry simulation with no latent heating) to isolate the role of the heated terrain. This "dry simulation" was conducted for the period spanning 12:00 UTC, 1 February, to 23:00 UTC, 4 February 2010. The same input and boundary conditions are used as before. Again, the first $12 \mathrm{~h}$ are discarded and hourly data for days 2-4 February are composited for analysis. Results from this dry simulation are also shown in Fig. 8 and demonstrate a significantly reduced diurnal cycle compared to the results from offshore and nooffshore days. This suggests that much of the diurnal cycle in moisture convergence seen in the full physics simulations is convectively induced. Nonetheless, the differences in background environmental conditions around the northern coast between offshore and no-offshore days are highly suggestive of large-scale controls on the occurrence of these offshorepropagating systems. 

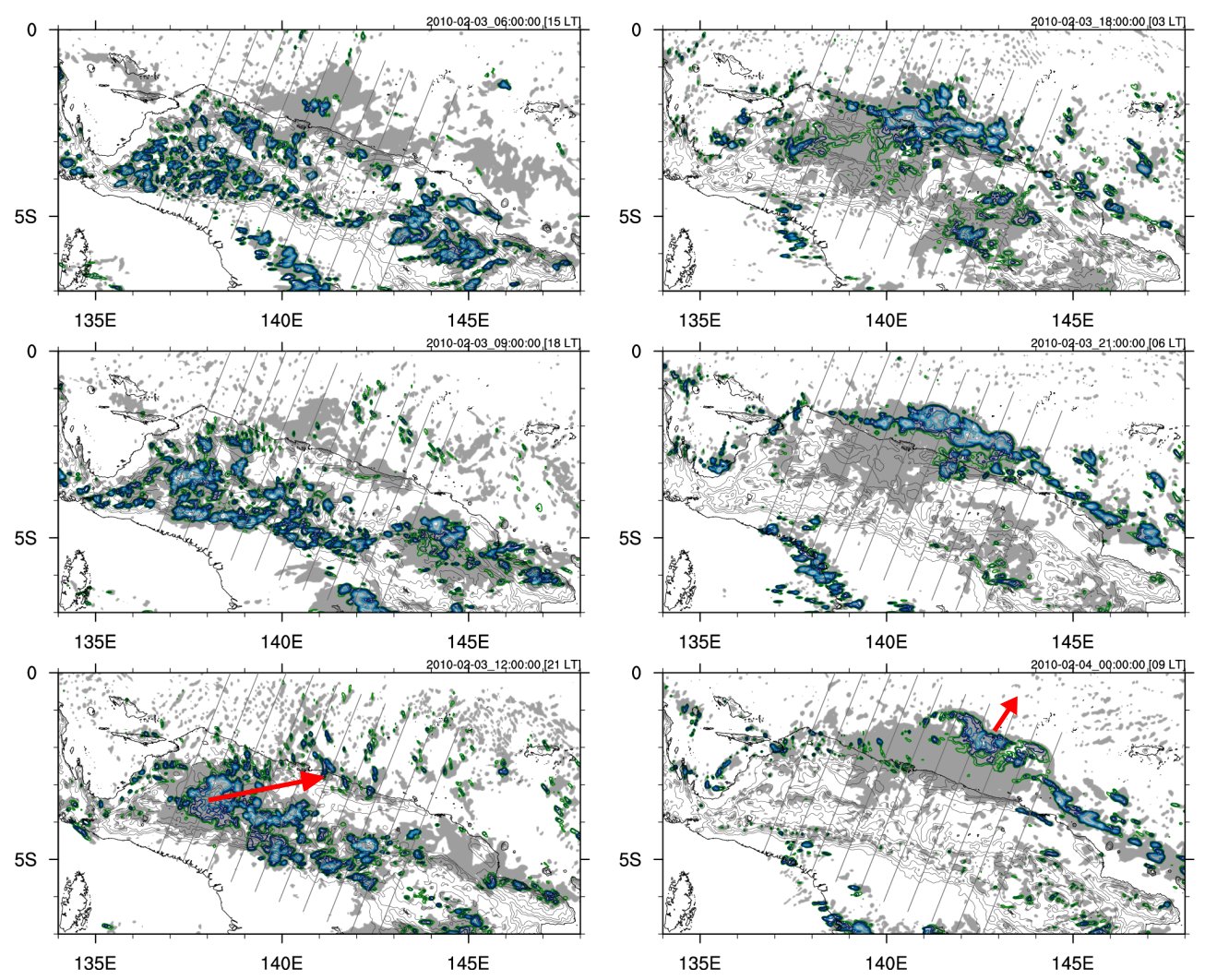

Figure 9. Multi-stage evolution of offshore squall-line propagation for a modelled storm on 3 February 2010, as shown by total column cloud (grey shade) and rainfall (green-blue contours) during the early evening (left panels) and early morning (right panels). The red arrows indicate the approximate direction of storm motion over land and water.

\subsubsection{Propagating squall-line}

As exemplified by Fig. 4a the temporal evolution of the offshore-propagating convective system manifests through a multi-stage process. First, convective systems form over the peaks and move slowly downslope in the early evening. Around this time the intensity of the rainfall increases as systems become more organised. Just after midnight, the convective systems reform near the coast and begin to propagate offshore at around $5 \mathrm{~m} \mathrm{~s}^{-1}$. This process of system reorganisation, coastal orientation, and propagation offshore is illustrated by Fig. 9 for a representative event (3 February 2010).

The vertical structure and system-relative flow for the same event post-midnight is shown in Fig. 10. There is a large cloud mass over land as well as an isolated convective system near the coast. These systems merge by 02:00 LT. At 06:00 LT the convective system has evolved into a large squall line. The squall line approximately corresponds to the standard leading-line trailing stratiform archetype (e.g. Houze, 2004). The system relative wind features a stagnation point at the surface - identifying the leading edge of a propagating surface cold pool, middle-level inflow that is linked with rearward directed upper-level outflow, and rear-to-front flow below the anvil characteristic of a mesoscale downdraft.

\subsubsection{Gravity waves}

Previous studies (e.g. Mapes et al., 2003; Love et al., 2011) have explained cases of offshore-propagating convective systems in the tropics as a result of gravity wave processes. This is because in those cases, the systems extended further and/or faster than would be expected for land breezes or katabatic winds generated by the terrain. Mapes et al. (2003) described a mechanism for the formation of offshore convection as a result of diurnally forced gravity waves that are generated primarily by the boundary layer heating and cooling over the elevated terrain. The nocturnal phase of these waves was shown to propagate offshore at about $15 \mathrm{~m} \mathrm{~s}^{-1}$ and destabilise the environment, which promoted convective development. Love et al. (2011) considered this further and argued that stratiform cooling from convective systems over land was an important contributor to the generation of these waves. However, as shown previously, the most intense rainfall signal from offshore convective systems herein propagates at about $5 \mathrm{~m} \mathrm{~s}^{-1}$, which is considerably slower than the gravity waves considered by previous studies; instead the offshore-propagating systems appear as squall lines maintained by a surface cold pool. Indeed, Tulich and Mapes (2008) showed that surface-based cold pools move between 

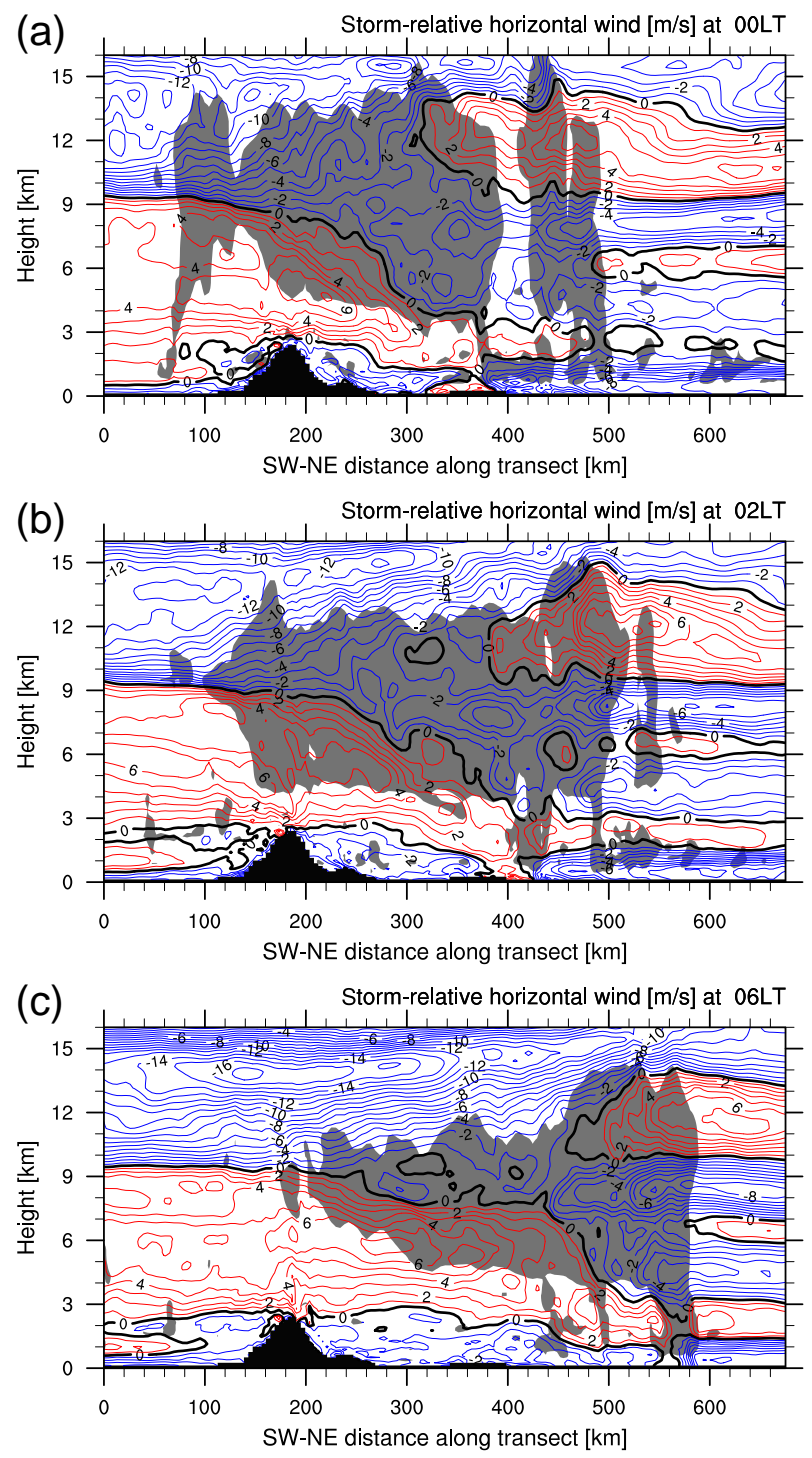

Figure 10. Mean system-relative horizontal wind along the section, as averaged across the transects seen in Fig. 1a at (a) 00:00 LT, (b) 02:00 LT, and (c) 06:00 LT for a modelled system on 3 February 2010. Red is positive. Total cloud $\geq 0.05 \mathrm{~g} \mathrm{~kg}^{-1}$ is shaded grey.

3 and $7 \mathrm{~m} \mathrm{~s}^{-1}$. In this section, we consider these mechanisms further to help understand whether gravity waves play any role in the dynamics of the offshore-propagating convection seen in the simulations.

Figure 11 shows vertical cross-sections of temperature perturbations that propagate from the terrain. Both offshore and no-offshore days show very similar structures. At 15:00 LT, daytime boundary layer heating is evident over land, extending primarily to the depth of the terrain peak. There is an associated temperature perturbation, viz. a gravity wave, that extends offshore but is deeper; at the rightmost limits of the shown diagrams manifests as a wave structure with a vertical wavelength equal to about $10 \mathrm{~km}$. (Such a wavelength is often referred to as the " $n=3$ wave", as here it corresponds to three antinodes within the troposphere that extends to a depth of about $15 \mathrm{~km}$ in our case.) By 23:00 LT the opposite phase of this wave is evident offshore, i.e. heating overlying cooling; the cooling is linked directly to the depth of precipitation below the melting level over land, as shown by the $0.05 \mathrm{~g} \mathrm{~kg}^{-1}$ rain mixing ratio contour. That is, the cool anomaly appears to be generated by the evaporative cooling associated with the land-based convection. Note that the wave structure is not purely sinusoidal since the lower half-wavelength has the strongest amplitude. Arguably, what the simulated convection is forcing is a strong $4-5 \mathrm{~km}$ deep cold anomaly near the surface with weaker alternating sign anomalies aloft. At 03:00 LT, when the convective system is mature and propagating offshore, the temperature anomalies are mostly negative offshore but there is still evidence of the low-level (about $4 \mathrm{~km}$ deep) cool anomaly extending well ahead of the convection. The cool low-level gravity wave anomalies that propagate offshore have the potential to destabilise the offshore environment and promote or initiate further convection. Previous studies (e.g. Lane and Reeder, 2001; Mapes, 1993) have shown how deep convection acts to excite these gravity waves - termed the "slow mode" by Tulich et al. (2007) - in the forward environment.

To consider the time evolution of the offshore environment associated with the passage of the gravity waves, consider time-height sections of CAPE, rainfall, and $3 \mathrm{~km}$ temperature perturbation (Fig. 12). Here $3 \mathrm{~km}$ is chosen as it is the approximate depth of the maximum cool anomaly in Fig. 11 at 03:00 LT. Red lines overlaid on the images mark the onset of offshore rainfall (cf. Fig. 12b), and blue lines mark the transition from the warm to cool anomaly offshore (cf. Fig. 12c.)

The propagation of the gravity wave signal is evident in Fig. 12c, with the offshore temperature anomaly possessing a diurnal period and coherent offshore propagation at a speed of approximately $15 \mathrm{~m} \mathrm{~s}^{-1}$. The phase speed of a hydrostatic gravity wave is $c=N \lambda_{z} / 2 \pi+U$, where $N$ is the Brunt-Väisälä frequency, $\lambda_{z}$ is the vertical wavelength, and $U$ is the mean horizontal flow. For values of $N \approx 0.01 \mathrm{~s}^{-1}$ and neglecting the mean low-level flow (which is only a few $\mathrm{m} \mathrm{s}^{-1}$ ), this $15 \mathrm{~m} \mathrm{~s}^{-1}$ phase speed corresponds to an approximate vertical wavelength of $10 \mathrm{~km}$, which matches those waves in Fig. 11. (Incidentally, this is also the speed of the cool anomalies considered by Mapes et al., 2003).

Of relevance, the onset of the cool gravity wave anomaly offshore corresponds to a notable increase in the CAPE that peaks during the passage of the cool anomaly. That is, the offshore-propagating gravity wave has destabilised the offshore environment by decreasing the environmental (virtual) temperature at lower altitudes. This, coupled with the concurrent increase in boundary layer moisture convergence (cf. Fig. 8), explains the strong growth in CAPE offshore. During the cool anomaly, the offshore-propagating squall line propagates into this destabilised offshore environment (albeit at 

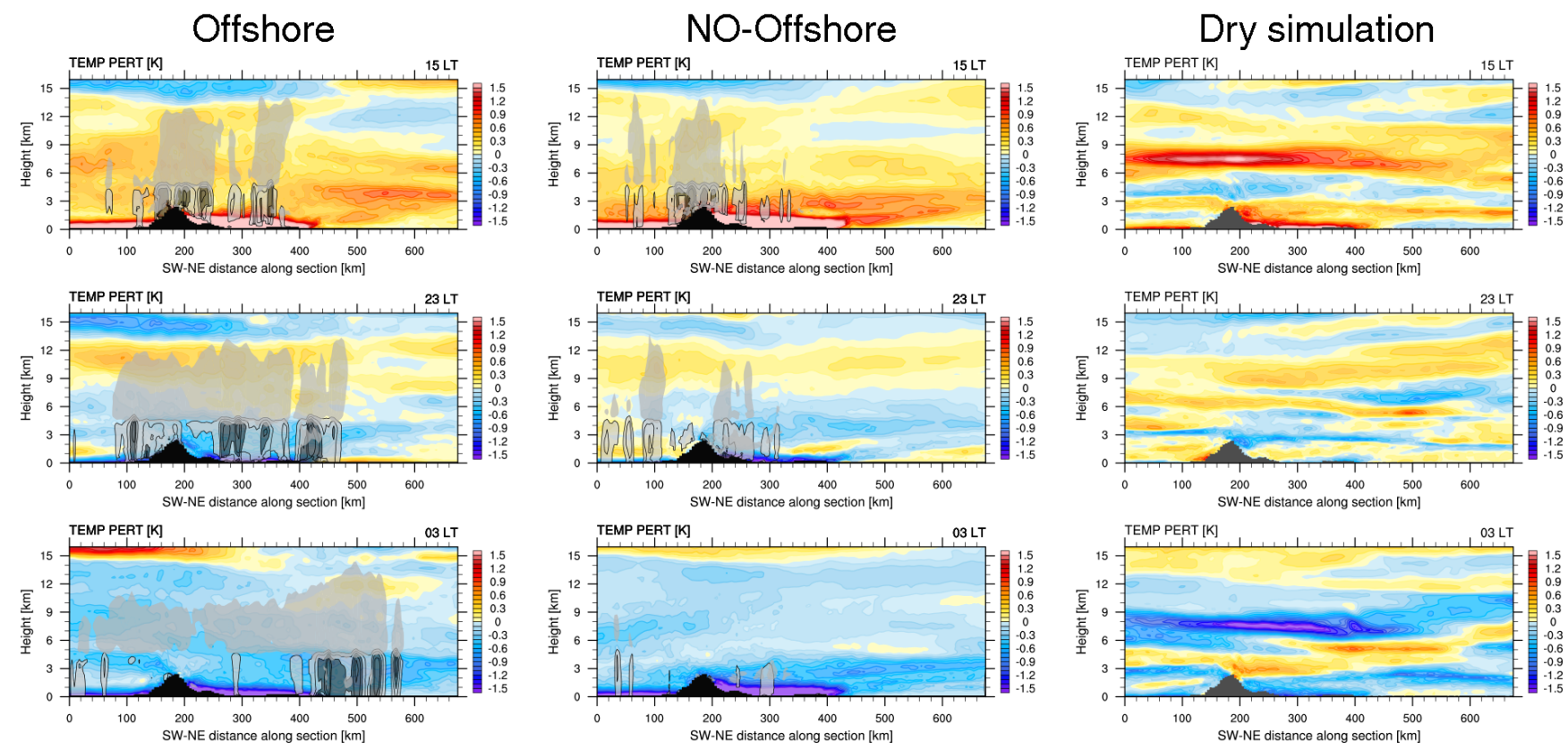

Figure 11. Temperature perturbations from daily mean (colours) for offshore (left panels), no-offshore (middle panels), and dry simulation (right panels) at 15:00, 23:00, and 03:00 LT. Total condensate greater $0.05 \mathrm{~g} \mathrm{~kg}^{-1}$ is shaded grey; rain areas are contoured every $0.05 \mathrm{~g} \mathrm{~kg}^{-1}$ in black with regions greater than $0.15 \mathrm{~g} \mathrm{~kg}^{-1}$ shaded dark grey. The averaged terrain profile is shaded black.
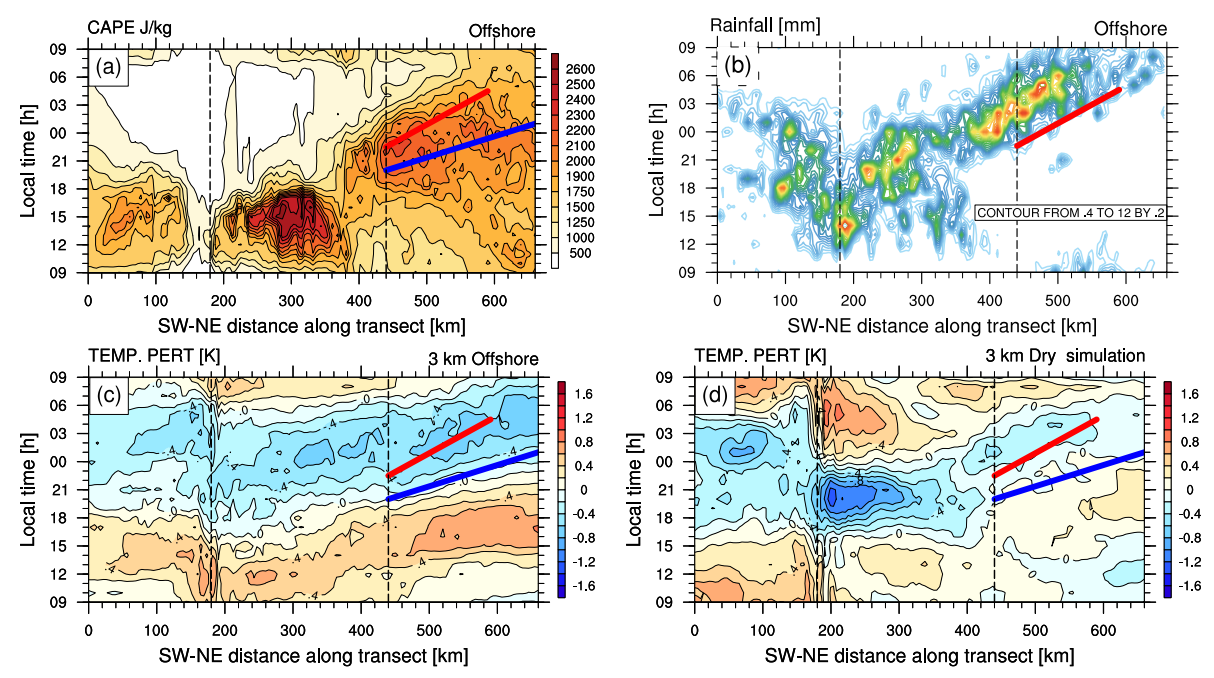

Figure 12. Mean diurnal cycles of (a) CAPE, (b) rainfall, and (c) temperature perturbations from daily mean for offshore days. (d) As in panel (c) but for the dry simulation. Dashed vertical lines indicate the position of the ridge and northern coastline respectively. The phase speed of the red line (denoting rainfall onset) is $\sim 8 \mathrm{~m} \mathrm{~s}^{-1}$ while the phase speed of the blue line (denoting cooling onset) is $\sim 15 \mathrm{~m} \mathrm{~s}{ }^{-1}$.

a speed slower than the gravity wave); the onset of rainfall occurs within the cold wave anomaly where that CAPE is increased. Thus, from these and results presented earlier it appears that the convective system (maintained by the surface cold pool) is not initiated by the gravity wave mode but instead the system moves into an environment that has been destabilised by the cool phase of the gravity wave shortly before its arrival. Thus, the wave may play a role in enhancing the squall line and promoting its longevity, but ulti- mately the squall line appears to originally form independent of the wave. Nevertheless, the phase speed corresponding to the rainfall onset $\left(8 \mathrm{~m} \mathrm{~s}^{-1}\right)$ suggests preferential triggering of convection ahead of the main squall line. Such a phase speed is reminiscent of the "gust-front mode" identified by Tulich and Mapes (2008), who demonstrated the efficacy of this shallow gravity wave mode in initiating subsequent convection ahead. Inspection of Fig. 10 does indicate vertical wavelength structures of about $4-5 \mathrm{~km}$ both within and ahead 
of the main convective line. This is consistent with the short vertical wavelength of the "gust-front" mode $(\sim 5 \mathrm{~km})$. Furthermore, the cool temperature anomalies in the lower free troposphere ahead of the system depict a local minimum at $\sim 1 \mathrm{~km}$ (Fig. 11, leftmost bottom two panels). Again, this is consistent with the temperature structures shown by Tulich and Mapes (2008) for the "gust-front" mode (their Fig. 3b), suggesting the potential importance of this mode for triggering convection.

To consider the relative roles of the topographic and boundary layer heating/cooling vs. the diabatic forcing from convection in generating the gravity waves, results from the dry simulation are considered here. For the dry simulation (Fig. 12d) the cooling over land is larger than the full physics simulation, presumably due to increased nocturnal radiative cooling in the absence of clouds. Also, because boundary layer heating and cooling extends all the way to the coast, the anomalies over land appear stationary, fluctuating in phase with the diurnal cycle. In contrast, the offshore-propagating gravity wave signal is substantially weaker in amplitude with a slower propagation speed. This slower speed is consistent with the shallower cold anomaly (shorter gravity wave vertical wavelength) seen in Fig. 11. These results strongly suggest the importance of the convective diabatic forcing, in this case "stratiform cooling", in contributing to the generation of the offshore-propagating gravity waves that further destabilise the environment (consistent with the conclusions of Love et al., 2011). Nonetheless, boundary layer cooling (cf. Mapes et al., 2003) does force offshore-propagating waves that work in concert with the convectively generated waves.

As suggested by Fig. 11, the strength and depth of the offshore cool anomalies are very similar for offshore and nooffshore days. Similar time-distance analysis to Fig. 12 for no-offshore (not shown) demonstrates much similarity to offshore, including an increase in CAPE with the passage of the wave of similar magnitude. Though recall in the no-offshore case, the background CAPE is substantially smaller than in offshore due to less boundary layer convergence. This result suggests that the convection over land, which occurs in both cases, plays a key role in the wave generation.

\section{Conclusions}

This study has examined the diurnal cycle of rainfall over New Guinea using a series of convection-permitting model simulations using the WRF model. The simulations focus on February 2010, which is a period of suppressed regionalscale conditions chosen to maximise the local influence on the diurnal cycle. The primary focus of the study and analysis was on the occurrence and dynamics of the offshorepropagating convective systems that contribute to the earlymorning precipitation maximum to the north-east of New Guinea.
The model simulations are configured with one-way nested domains, with the primary focus on results from a $4 \mathrm{~km}$ horizontal grid spacing domain. The modelled precipitation shows good spatial agreement with observed rainfall from the TRMM 3B42 product. However, the intensity of the modelled precipitation is larger than TRMM over the steep terrain. Better agreement between the model and the observations is found over Darwin, which has substantially lower topography than New Guinea. Additional simulations, over a 2-week period, using $1.33 \mathrm{~km}$ grid spacing show similar results and biases to the $4 \mathrm{~km}$ domain and lend support to using the $4 \mathrm{~km}$ domain over the month-long period.

The model simulations reproduce the occurrence and variability of convective systems that propagate offshore, to the north-east, of New Guinea during the night and early morning. These systems are linked to daytime convective systems over land, which reform near the coast around midnight and then propagate at about $5 \mathrm{~m} \mathrm{~s}^{-1}$ offshore as organised squall lines. The occurrence of the offshore systems is largely related to the background conditions. Days with offshore-propagating convection have more middle tropospheric moisture, larger CAPE, and greater low-level moisture convergence than days without offshore-propagating convection. Convection has similar characteristics over the terrain on both days with and without offshore propagation.

Gravity waves are also generated as part of the diurnal cycle and propagate offshore at about $15 \mathrm{~m} \mathrm{~s}^{-1}$. The cool phase of these waves (with negative low-level temperature anomalies) propagates offshore during the evening and early morning, which destabilises the offshore environment (increases the CAPE) immediately prior to the arrival of the organised convective systems. The forcing of the gravity waves is linked to precipitating convection over land because an additional experiment with no convection (viz. a dry simulation) shows weaker and slower gravity waves. The $15 \mathrm{~m} \mathrm{~s}^{-1}$ gravity wave does not initiate convection per se and it propagates faster than the squall lines, but by increasing the CAPE the wave makes the nocturnal offshore environment more conducive to deep convection and likely contributes to the longevity of the offshore-propagating squall line. However, it is possible that convection may be triggered by a "gustfront" mode moving slower at $8 \mathrm{~m} \mathrm{~s}^{-1}$ and corresponds to the offshore rainfall onset. Clearly, our understanding of these propagating systems would benefit from increased observations. For example, radiosonde launch sites located about $150 \mathrm{~km}$ offshore would be highly useful. In addition, radars at coastal sites and/or on ships could also observe the passage and structure of convective systems from land through to ocean. Such observations should form part of future field campaigns like the YMC (Years of the Maritime Continent).

These results highlight the importance of terrain and coastal effects and gravity waves in controlling the diurnal cycle over the Maritime Continent, especially the offshore precipitation maxima. However, these results have been limited in their scope as they only focus on one period of sup- 
pressed regional-scale activity due to an active MJO phase in the eastern Pacific/western hemisphere. The simulations are also only "convection permitting" and therefore do not necessarily resolve all the processes at play. Indeed, the structure of the diurnal cycle in the Maritime Continent and its variation with the passage of the MJO has been the focus of recent work (Peatman et al., 2014). In the context of offshore propagation and its sensitivity to MJO phase, our future work will focus on cases with different regional-scale conditions and higher model resolution.

Acknowledgements. The authors would like to acknowledge David Lee (formerly of the University of Melbourne, now at Los Alamos National Laboratory) for providing Fig. 3. The authors would also like to thank Tim Dunkerton (editor), Stefan Tulich, Mitchell Moncrieff, and an anonymous reviewer for helpful comments which improved the quality of the manuscript. This research was supported by the ARC Centre of Excellence for Climate System Science (CE1100010128). High-performance computing was provided by the National Computational Infrastructure (NCI) facility. Data analysis and visualisation were conducted with the NCAR Command Language (Version 6.2.1), Software, Boulder, Colorado: UCAR/NCAR/CISL/VETS, doi:10.5065/D6WD3XH5, 2014.

Edited by: T. J. Dunkerton

\section{References}

Barthlott, C. and Kirshbaum, D. J.: Sensitivity of deep convection to terrain forcing over mediterranean islands, Q. J. Roy. Meteor. Soc., 139, 1762-1779, doi:10.1002/qj.2089, 2013.

Biasutti, M., Yuter, S. E., Burleyson, C. D., and Sobel, A. H.: Very high resolution rainfall patterns measured by TRMM precipitation radar: seasonal and diurnal cycles, Clim. Dynam., 39, 239258, doi:10.1007/s00382-011-1146-6, 2012.

Bringi, V. N., Huang, G. J., Chandrasekar, V., and Keenan, T. D.: An areal rainfall estimator using differential propagation phase: Evaluation using a C-band radar and a dense gauge network in the tropics, J. Atmos. Ocean. Tech., 18, 1810-1818, doi:10.1175/1520-0426(2001)018<1810:AAREUD>2.0.CO;2, 2001.

Chen, Y., Ebert, E. E., Walsh, K. J. E., and Davidson, N. E.: Evaluation of TRMM 3B42 precipitation estimates of tropical cyclone rainfall using PACRAIN data, J. Geophys. Res.-Atmos., 118, 2184-2196, doi:10.1002/jgrd.50250, 2013.

Dee, D. P., Uppala, S. M., Simmons, A. J., Berrisford, P., Poli, P., Kobayashi, S., Andrae, U., Balmaseda, M. A., Balsamo, G., Bauer, P., Bechtold, P., Beljaars, A. C. M., van de Berg, L., Bidlot, J., Bormann, N., Delsol, C., Dragani, R., Fuentes, M., Geer, A. J., Haimberger, L., Healy, S. B., Hersbach, H., Hólm, E. V., Isaksen, L., Kållberg, P., Köhler, M., Matricardi, M., McNally, A. P., Monge-Sanz, B. M., Morcrette, J.-J., Park, B.K., Peubey, C., de Rosnay, P., Tavolato, C., Thépaut, J.-N., and Vitart, F.: The ERA-Interim reanalysis: configuration and performance of the data assimilation system, Q. J. Roy. Meteor. Soc., 137, 553-597, doi:10.1002/qj.828, 2011.
Fujita, M., Kimura, F., and Yoshizaki, M.: Morning precipitation peak over the Strait of Malacca under a calm condition, Mon. Weather Rev., 138, 1474-1486, doi:10.1175/2009MWR3068.1, 2010.

Houze, R. A.: Mesoscale convective systems, Rev. Geophys., 42, RG4003, doi:10.1029/2004RG000150, 2004.

Houze, R. A., Geotis, S. G., Marks, F. D., and West, A. K.: Winter monsoon convection in the vicinity of North Borneo. Part I: Structure and time variation of the clouds and precipitation, Mon. Weather Rev., 109, 1595-1614, doi:10.1175/15200493(1981)109<1595:WMCITV>2.0.CO;2, 1981.

Huffman, G. J., Adler, R. F., Bolvin, D. T., and Nelkin, E. J.: The TRMM Multi-satellite Precipitation Analysis (TMPA), in: Satellite Rainfall Applications for Surface Hydrology, chap. 1, edited by: Hossain, F. and Gebremichael, M., Springer Verlag, the Netherlands, 3-22, doi:10.1007/978-90-481-2915-7_1, 2010.

Kikuchi, K. and Wang, B.: Diurnal precipitation regimes in the global tropics, J. Climate, 21, 2680-2696, doi:10.1175/2007JCLI2051.1, 2008.

Lane, T. P. and Reeder, M. J.: Convectively generated gravity waves and their effect on the cloud environment, J. Atmos. Sci., 58, 2427-2440, doi:10.1175/15200469(2001)058<2427:CGGWAT>2.0.CO;2, 2001.

Liberti, G. L., Chéruy, F., and Desbois, M.: Land effect on the diurnal cycle of clouds over the TOGA COARE area, as observed from GMS IR data, Mon. Weather Rev., 129, 1500-1517, doi:10.1175/1520-0493(2001)129<1500:LEOTDC>2.0.CO;2, 2001.

Lo, J. C.-F., Yang, Z.-L., and Pielke Sr., R. A.: Assessment of three dynamical climate downscaling methods using the Weather Research and Forecasting (WRF) model, J. Geophys. Res., 113, D09112, doi:10.1029/2007JD009216, 2008.

Love, B. S., Matthews, A. J., and Lister, G. M. S.: The diurnal cycle of precipitation over the Maritime Continent in a highresolution atmospheric model, Q. J. Roy. Meteor. Soc., 137, 934947, doi:10.1002/qj.809, 2011.

Mapes, B. E.: Gregarious tropical convection, J. Atmos. Sci., 50, 2026-2037, doi:10.1175/15200469(1993)050<2026:GTC>2.0.CO;2, 1993.

Mapes, B. E., Warner, T. T., and Xu, M.: Diurnal patterns of rainfall in Northwestern South America. Part III: Diurnal gravity waves and nocturnal convection offshore, Mon. Weather Rev., 131, 830-844, doi:10.1175/15200493(2003)131<0830:DPORIN>2.0.CO;2, 2003.

Matthews, A. J., Pickup, G., Peatman, S. C., Clews, P., and Martin, J.: The effect of the Madden-Julian oscillation on station rainfall and river level in the Fly River system, Papua New Guinea, J. Geophys. Res.-Atmos., 118, 10926-10935, doi:10.1002/jgrd.50865, 2013.

May, P. T., Long, C. N., and Protat, A.: The diurnal cycle of the boundary layer, convection, clouds, and surface radiation in a coastal monsoon environment (Darwin, Australia), J. Climate, 25, 5309-5326, doi:10.1175/JCLI-D-11-00538.1, 2012.

Moncrieff, M. W., Waliser, D. E., Miller, M. J., Shapiro, M. A., Asrar, G. R., and Caughey, J.: Multiscale convective organization and the YOTC virtual global field campaign, B. Am. Meteorol. Soc., 93, 1171-1187, doi:10.1175/BAMS-D-11-00233.1, 2012.

Mori, S., June-Ichi, H., Tauhid, Y. I., Yamanaka, M. D., Okamoto, N., Murata, F., Sakurai, N., Hashiguchi, H., and 
Sribimawati, T.: Diurnal land-sea rainfall peak migration over Sumatera Island, Indonesian Maritime Continent, observed by TRMM satellite and intensive rawinsonde soundings, Mon. Weather Rev., 132, 2021-2039, doi:10.1175/15200493(2004)132<2021:DLRPMO>2.0.CO;2, 2004.

Peatman, S. C., Matthews, A. J., and Stevens, D. P.: Propagation of the Madden-Julian oscillation through the Maritime Continent and scale interaction with the diurnal cycle of precipitation, Q. J. Roy. Meteor. Soc., 140, 814-825, doi:10.1002/qj.2161, 2014.

Qian, J.-H.: Why precipitation is mostly concentrated over islands in the Maritime Continent, J. Atmos. Sci., 65, 1428-1441, doi:10.1175/2007JAS2422.1, 2008.

Skamarock, W. C., Klemp, J. B., Dudhia, J., Gill, D. O., Baker, D. M., Duda, M. G., Huang, X.-Y., Wang, W., and Powers, J. G.: A Description of the Advanced Research WRF Version 3, NCAR/TN-47, NCAR, Boulder, CO, USA, 113 pp., 2008.

Tulich, S. N. and Mapes, B. E.: Multiscale convective wave disturbances in the tropics: insights from a two-dimensional cloud-resolving model, J. Atmos. Sci., 65, 140-155, doi:10.1175/2007JAS2353.1, 2008.

Tulich, S. N., Randall, D. A., and Mapes, B. E.: Vertical-mode and cloud decomposition of large-scale convectively coupled gravity waves in a two-dimensional cloud-resolving model, J. Atmos. Sci., 64, 1210-1229, doi:10.1175/JAS3884.1, 2007.
Wapler, K. and Lane, T. P.: A case of offshore convective initiation by interacting land breezes near Darwin, Australia, Meteorol. Atmos. Phys., 115, 123-137, doi:10.1007/s00703-011-01806, 2012.

Wapler, K., Lane, T. P., May, P. T., Jakob, C., Manton, M. J., and Siems, S. T.: Cloud-system-resolving model simulations of tropical cloud systems observed during the Tropical Warm PoolInternational Cloud Experiment, Mon. Weather Rev., 138, 5573, doi:10.1175/2009MWR2993.1, 2010.

Wu, P., Manabu, D., and Matsumoto, J.: The formation of nocturnal rainfall offshore from convection over western Kaliman$\tan$ (Borneo) Island, J. Meteorol. Soc. Jpn., 86A, 187-203, doi:10.2151/jmsj.86A.187, 2008.

Wu, P., Hara, M., Hamada, J.-I., Yamanaka, M. D., and Kimura, F.: Why a large amount of rain falls over the sea in the vicinity of Western Sumatra Island during nighttime, J. Appl. Meteorol. Clim., 48, 1345-1361, doi:10.1175/2009JAMC2052.1, 2009.

Yang, G.-Y. and Slingo, J.: The diurnal cycle in the tropics, Mon. Weather Rev., 129, 784-801, doi:10.1175/15200493(2001)129<0784:TDCITT>2.0.CO;2, 2001.

Zhou, L. and Wang, Y.: Tropical Rainfall Measuring Mission observation and regional model study of precipitation diurnal cycle in the New Guinean region, J. Geophys. Res., 111, 1-18, doi:10.1029/2006JD007243, 2006. 